\title{
Targeting the Trimolecular Complex: The Pathway Towards Type 1 Diabetes Prevention
}

\author{
Aaron W. Michels, MD
}

\begin{abstract}
George Eisenbarth devoted his life to understanding the basic immunology of the autoimmune polyglandular syndromes and type 1 diabetes, while providing exceptional clinical care to individuals afflicted with these disorders. Over the last 5 years, I was privileged to know George Eisenbarth as a mentor, colleague, and friend. His enthusiasm for science and specifically understanding the basic immunology of type 1 diabetes was infectious. George was the first to initially hypothesize that type 1 diabetes is a chronic autoimmune disorder. He made diabetes a predictable disease by developing biochemical assays to measure islet autoantibodies and provided this technology worldwide to researchers and the medical community. His work identifying and detecting islet autoantibodies allowed for clinical intervention trials aimed at preventing type 1 diabetes. George worked fervently to prevent the disease. During my time as a fellow in George's laboratory and faculty member at the Barbara Davis Center for Diabetes, we focused our efforts for diabetes prevention at the trimolecular complex (human leukocyte antigen molecule, self-peptide, and T cell receptor), which plays a pivotal role in diabetes pathogenesis. It is our belief that targeting this complex with safe and specific therapies will lead to the prevention of type 1 diabetes and an improved understanding as to why diabetes develops.
\end{abstract}

\section{Introduction}

T YPE 1 DIABETES (T1D) RESUlts from the body's immune system specifically targeting and destroying pancreatic $\beta$ cells. George Eisenbarth initially characterized T1D as a chronic autoimmune disorder in $1986 .{ }^{1}$ He postulated that T1D had stages in development and that each stage could be detected with immune markers (islet autoantibodies and $\mathrm{T}$ cell responses) and eventually metabolic abnormalities (impaired first-phase insulin release, abnormal oral glucose tolerance, and eventually no endogenous insulin production). The concept of stages in autoimmune T1D still exists today and has served as a model for making diabetes predictable and intervening to prevent disease onset. ${ }^{2,3}$ Currently T1D is a predictable disease by measuring islet autoantibodies (insulin, glutamic acid decarboxylase [GAD], islet antigen 2 [IA-2], and zinc transporter 8 [ZnT8]); however, the disease cannot yet be prevented. Furthermore, T1D incidence has doubled in many industrialized nations over the last 20 years, with children less than 5 years of age being diagnosed more frequently. ${ }^{4-6}$ George understood the commitment it took for individuals and families with diabetes to live with the disease. It was his goal to ease the burden of diabetes by preventing and ultimately curing the disease. His life's work contributed immensely to understanding the genetic risk and immunology of T1D. The discoveries throughout his career laid the foundation for targeting the trimolecular complex (human leukocyte antigen [HLA] molecule, peptide, and CD4 T cell receptor [TCR]) to safely and specifically prevent T1D onset.

\section{The Trimolecular Complex}

The trimolecular complex is composed of three components: an HLA molecule, self-peptide such as insulin, and a TCR on a CD4 T cell. HLA genes predispose risk for developing T1D and encode proteins, major histocompatibility complex (MHC) molecules, which present processed peptides to T cells. ${ }^{7}$ The basic structural components of the trimolecular complex are depicted in the center of Figure 1. In his 2009 Banting Lecture at the American Diabetes Association Annual Meeting, George compared the elements of the trimolecular complex to a hotdog in a bun ${ }^{8}$ : the bun is the MHC molecule, the hotdog is a peptide, and the TCR would be the individual eating the hot dog. In a typical bite, a person (TCR) consumes bun and peptide, analogous to a $\mathrm{T}$ cell interacting with a peptide bound to a MHC molecule. Understanding complex immunology and communicating those concepts to others in a comprehensible manner was a strength George possessed.

George initially reported that HLA genes were associated with autoimmune polyglandular failure in a New England Journal of Medicine article in $1978 .^{9}$ It was later discovered that certain HLA molecules, termed DQ8 and DQ2, predispose

Barbara Davis Center for Childhood Diabetes, University of Colorado Denver, Aurora, Colorado. 


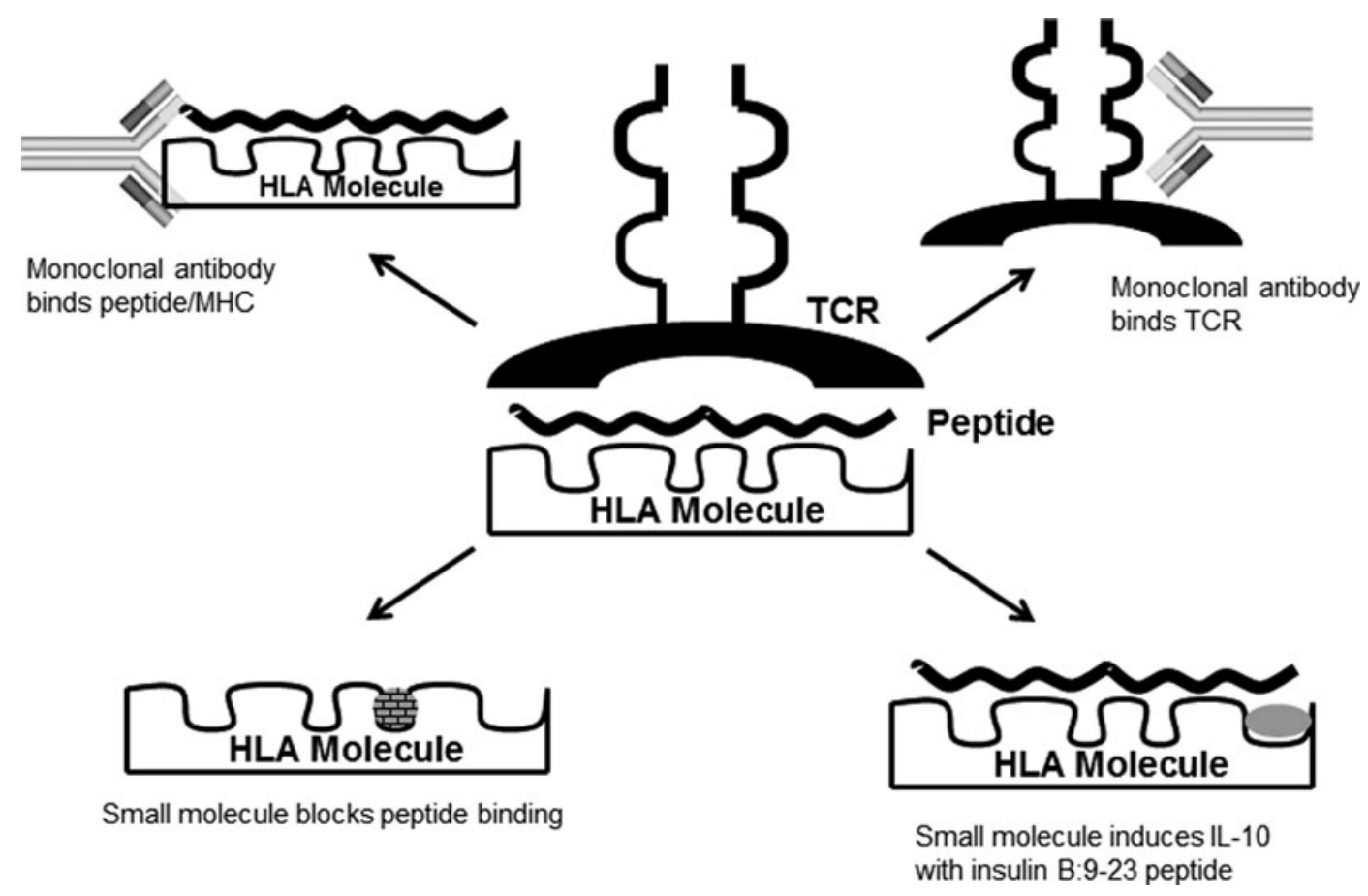

FIG. 1. The components of the trimolecular complex and therapeutic approaches for targeting. The trimolecular complex consisting of a T cell receptor (TCR)-peptide-human leukocyte antigen (HLA) molecule. In order to block interactions, (1) a small molecule can occupy a pocket in a specific major histocompatibility complex (MHC) peptide binding groove, blocking peptide presentation to T cells, (2) a small molecule, such as glyphosine, can bind the MHC molecule and with an appropriate peptide induce a protective interleukin (IL)-10 response, (3) a monoclonal antibody can bind a specific peptide/MHC complex, thereby blocking $\mathrm{T}$ cell activation, or (4) a monoclonal antibody targets a specific TCR.

risk for developing T1D. ${ }^{10}$ In fact, genome-wide association studies showed that the odds ratio for developing diabetes ranged from 6.5 to 11 when either of these genes is present. ${ }^{11,12}$ Approximately $90 \%$ of all individuals with T1D have either a $D Q 8$ and/or a $D Q 2$ gene, with $50-60 \%$ of all T1D patients having $D Q 8$. Furthermore, a certain HLA molecule, DQ6 (DQB*0602), protects from diabetes development with an odds ratio of only 0.03 , indicating that T1D develops extremely infrequently when this gene is present. ${ }^{11}$

With the understanding and knowledge that HLA genes contribute to T1D risk, proteins and peptides presented by these MHC molecules needed to be identified. George worked to identify islet antigens and then measure antibodies to these proteins in T1D patients and those at risk for developing diabetes (those with high risk HLA genotypes and a family history of T1D). ${ }^{13-18}$ Currently there are four islet autoantibodies that can be measured directed against insulin, GAD, a tyrosine phosphatase-like protein (IA-2), and the zinc transporter ${ }^{19,20}$; all islet autoantibody assays are now available commercially throughout the world. Recent work from George's laboratory has resulted in the development of nonradioactive islet autoantibody assays that are more sensitive and specific than the previously used radioimmunoassays. ${ }^{21}$ George had a particular interest in the insulin molecule, as evidenced by immunotherapy trials using both subcutaneous and oral insulin to prevent diabetes onset. ${ }^{22-24}$ In a spontaneous mouse model of autoimmune diabetes, the non-obese (NOD) mouse, he and his lab discovered that insulin is a primary autoantigen in the disease process. Specifically, insulin B chain amino acids 9-23 (B:9-23) contained an epitope necessary to drive $\mathrm{T}$ cell destruction of islet $\beta$-cells, as mutating a single amino acid in the insulin B:9-23 peptide sequence resulted in all mice remaining euglycemic and free of insulitis. ${ }^{25,26}$ Of note is that the insulin B:9-23 amino acid sequence is identical in the mouse and the human. The NOD mouse model parallels human T1D in having homologous genes encoding MHC molecules predisposing disease risk, development of insulin autoantibodies, and spontaneous development of $\mathrm{T}$ cell infiltration in islets. ${ }^{27}$ Recent analysis of the Diabetes Autoimmunity Study in the Young (DAISY) and Type 1 Diabetes Prediction and Prevention Project (DIPP) cohorts, which were screened for islet autoantibodies beginning at birth, revealed that insulin autoantibody titers correlate to diabetes progression (i.e., the higher the insulin autoantibody titers, the earlier in life diabetes developed, and lower titers had longer time periods to diabetes onset). ${ }^{28,29}$ Insulin has an important role in the development of T1D, especially in young children diagnosed with diabetes.

The final component of the trimolecular complex is receptors on T cells that recognize peptides presented by the MHC molecule. Studying T cells in the peripheral blood of patients has been an arduous task. ${ }^{30}$ However, recent studies may shed light on the manner in which insulin peptides are presented by MHC molecules to T cells. These studies highlight the importance of the "register" of insulin peptide binding to MHC molecules such that polymorphisms in HLA genes may lead to identical insulin peptides being presented, or "shown," to T cells in different registers. ${ }^{31-33}$ For example, we hypothesize that the insulin B:9-23 peptide may be presented differently by HLA-DQ8 or -DQ2 as opposed to the protective 
HLA-DQ6. Development of T cells with specificity for insulin may be changed depending upon a given HLA molecule such that DQ8 and DQ2 have the potential to lead to diabetes development. George wholeheartedly believed that the studying the components of the insulin trimolecular complex in the mouse and the human would lead to a better understanding as to why T1D develops.

\section{Therapies Targeting the Trimolecular Complex}

With the components of the trimolecular complex in place, George hypothesized that targeting each part may lead to novel therapies capable of preventing T1D in humans (Fig. 1). As a new energetic Fellow in George's lab, one of my initial projects was to target the MHC Class II molecule of the NOD mouse and DQ8, the homologous molecule in the human. With our collaborators from the University of Florida in Gainesville, in silico molecular modeling and docking with a supercomputer were used to identify potential small "drug-like" molecules capable of binding to pockets along the MHC peptide binding groove. A library of approximately 140,000 compounds from the National Institute of Health Developmental Therapeutics Program was screened in which each compound was placed in 1,000 orientations by a supercomputer into each of four pockets that anchor peptides to MHC molecules. Those small molecules with the highest predicted energy of binding were screened with a bioassay in George's lab. We were able to identify several compounds that blocked peptide binding specifically to a given MHC molecule, which resulted in T cells not being activated. One compound, tetraazatricyclododecane, blocked stimulation of $\mathrm{T}$ cells responding to whole insulin, necessitating endocytosis, processing, and presentation of insulin peptides. The compound also inhibited $\mathrm{T}$ cell activation in the presence of whole NOD islets, which have been shown to contain insulin peptides including B:9-23. ${ }^{34}$ Tetraazatricyclododecane was also predicted to bind to the human DQ8 peptide-binding groove and blocked activation of a human B:9-23-responsive $\mathrm{T}$ cell. ${ }^{35}$ It is conceivable that small drug molecules that specifically block DQ8 antigen presentation to $\mathrm{T}$ cells will delay or prevent diabetes onset.

To our surprise, we found several compounds effective at enhancing $\mathrm{T}$ cell responses. One of these compounds, glyphosine, was studied in further detail and found to enhance protective $\mathrm{T}$ cell responses. In the presence of glyphosine and the insulin B:9-23 peptide, interleukin (IL)-10 was produced from both NOD mouse spleen cells and human peripheral blood mononuclear cells from T1D patients having HLA DQ8. ${ }^{35}$ IL-10 is an anti-inflammatory cytokine and is associated with regulatory T cells. ${ }^{36,37}$ Furthermore, glyphosine was able to prevent diabetes onset in the NOD mouse while therapy was administered. We hypothesize that glyphosine changes the register of insulin B:9-23 presentation to $\mathrm{T}$ cells resulting in an IL-10 response. ${ }^{38}$

Using the trimolecular complex as a roadmap to design novel and specific therapies for diabetes prevention, others have had success developing and preventing diabetes in preclinical models. Li Zhang, a fellow in George's lab, developed a monoclonal antibody that binds to both the insulin B:9-23 peptide and MHC molecule of the NOD mouse. ${ }^{39}$ Interfering with peptide presentation then blocks the ability of a $\mathrm{T}$ cell to become activated. Conceptually, a monoclonal antibody to any peptide/MHC complex could be generated for disease intervention as long as the pathogenic peptide and register of binding to a MHC molecule are known.

Antigen-specific therapies have been used in several clinical intervention trials for diabetes prevention and in new-onset patients. ${ }^{40}$ The insulin B:9-23 peptide has been well documented to prevent and delay diabetes onset in NOD mice. ${ }^{41,42}$ A recent study using knowledge regarding the "register of binding" to a MHC molecule found that a low dose of an insulin B:9-23 mimotope protected against diabetes in NOD mice early in the disease course before insulin autoantibodies developed. ${ }^{43}$ The mimotope peptide had a single amino acid substitution (B22 arginine to glutamic acid) allowing binding to the mouse MHC Class II molecule in the appropriate register for $\mathrm{T}$ cell activation. Treatment with a continuous low dose of the mimotope peptide but not native insulin B:9-23 resulted in regulatory $\mathrm{T}$ cells and diabetes prevention. The register of peptide presentation by a given MHC molecule, dose, and frequency of dosing are all important considerations in antigen-specific therapies for T1D. ${ }^{40,44}$

Finally, therapies targeting TCRs involved in diabetes onset in rat models of autoimmune diabetes have been assessed. Specific TCRs in these rat models have been targeted with a monoclonal antibody to prevent diabetes development. A specific $\beta$-chain of the TCR, V $\beta 13$, is found in the CD4 T cells infiltrating the islets in these animal models. ${ }^{45}$ A depleting monoclonal antibody directed against $\mathrm{V} \beta 13$ prevented diabetes onset in a spontaneous autoimmune diabetes rat model and a model in which diabetes is induced by activation of the innate immune system. ${ }^{46}$

\section{Conclusions}

Our foundation for understanding T1D pathogenesis as an immunologic autoimmune disorder occurring in stages comes from the lifelong work of George Eisenbarth. As previously mentioned, T1D is a predictable disease because of the biochemical islet autoantibody assays developed by George and his colleagues. With the ability to predict disease development, diabetes prevention will naturally follow. George was passionate about preventing diabetes throughout his career. The focus of designing safe and specific therapies targeting the insulin trimolecular complex is a rational approach. Having a well-defined molecular target and tailoring therapies to specific HLA genes is truly personalized medicine, which George believed would ultimately prevent T1D. Translating these novel therapies from bench to bedside was a major focus for George, and the future holds promise for targeting the components of the trimolecular complex to prevent diabetes.

\section{Acknowledgments}

This work was supported by grants from the National Institute of Diabetes and Digestive Kidney Diseases (RO1 DK032083 and K08 DK09599), the Juvenile Diabetes Research Foundation, the Children's Diabetes Foundation, and the Brehm Coalition.

\section{Author Disclosure Statement}

No competing financial interests exist.

\section{References}

1. Eisenbarth GS: Type I diabetes mellitus. A chronic autoimmune disease. N Engl J Med 1986;314:1360-1368. 
2. Todd JA: Etiology of type 1 diabetes. Immunity 2010;32:457467.

3. Bluestone JA, Herold K, Eisenbarth G: Genetics, pathogenesis and clinical interventions in type 1 diabetes. Nature 2010;464:1293-1300.

4. Harjutsalo V, Podar T, Tuomilehto J: Cumulative incidence of type 1 diabetes in 10,168 siblings of Finnish young-onset type 1 diabetic patients. Diabetes 2005;54:563-569.

5. Harjutsalo V, Sjoberg L, Tuomilehto J: Time trends in the incidence of type 1 diabetes in Finnish children: a cohort study. Lancet 2008;371:1777-1782.

6. Bluestone JA, Mackay CR, O'Shea JJ, Stockinger B: The functional plasticity of $\mathrm{T}$ cell subsets. Nat Rev Immunol 2009;9:811-816.

7. Michels AW, Nakayama M: The anti-insulin trimolecular complex in type 1 diabetes. Curr Opin Endocrinol Diabetes Obes 2010;17:329-334.

8. Eisenbarth GS: Banting Lecture 2009: an unfinished journey: molecular pathogenesis to prevention of type $1 \mathrm{~A}$ diabetes. Diabetes 2010;59:759-774.

9. Eisenbarth GS, Wilson P, Ward F, Lebovitz HE: HLA type and occurrence of disease in familial polyglandular failure. N Engl J Med 1978;298:92-94.

10. Baschal EE, Eisenbarth GS: Extreme genetic risk for type 1A diabetes in the post-genome era. J Autoimmun 2008;31:1-6.

11. Erlich H, Valdes AM, Noble J, Carlson JA, Varney M, Concannon P, Mychaleckyj JC, Todd JA, Bonella P, Fear AL, Lavant E, Louey A, Moonsamy P; Type 1 Diabetes Genetics Consortium: HLA DR-DQ haplotypes and genotypes and type 1 diabetes risk: analysis of the Type 1 Diabetes Genetics Consortium Families. Diabetes 2008;57:1084-1092.

12. Concannon P, Rich SS, Nepom GT: Genetics of type 1A diabetes. N Engl J Med 2009;360:1646-1654.

13. Atkinson MA, Eisenbarth GS: Type 1 diabetes: new perspectives on disease pathogenesis and treatment. Lancet 2001;358:221-229.

14. Krischer JP, Cuthbertson DD, Yu L, Orban T, Maclaren N, Jackson R, Winter WE, Schatz DA, Palmer JP, Eisenbarth GS: Screening strategies for the identification of multiple antibody-positive relatives of individuals with type 1 diabetes. J Clin Endocrinol Metab 2003;88:103-108.

15. Nakayama M, Eisenbarth GS: Paradigm shift or shifting paradigm for type 1 diabetes. Diabetes 2012;61:976-978.

16. Eisenbarth GS: Prevention of type 1A diabetes mellitus. Endocr Pract 2012;18:745-749.

17. Sosinowski T, Eisenbarth GS: Type 1 diabetes: primary antigen/peptide/register/trimolecular complex. Immunol Res 2013;55:270-276.

18. Michels AW, Eisenbarth GS: Immune intervention in type 1 diabetes. Semin Immunol 2011;23:214-219.

19. Wenzlau JM, Juhl K, Yu L, Moua O, Sarkar SA, Gottlieb P, Rewers M, Eisenbarth GS, Jensen J, Davidson HW, Hutton JC: The cation efflux transporter ZnT8 (Slc30A8) is a major autoantigen in human type 1 diabetes. Proc Natl Acad Sci U S A 2007;104:17040-17045.

20. Nikolaeva N, Bemelman FJ, Yong SL, van Lier RAW, ten Berge IJM: Rapamycin does not induce anergy but inhibits expansion and differentiation of alloreactive human $\mathrm{T}$ cells. Transplantation 2006;81:445-454.

21. Yu L, Miao D, Scrimgeour L, Johnson K, Rewers M, Eisenbarth GS: Distinguishing persistent insulin autoantibodies with differential risk: nonradioactive bivalent proinsulin/insulin autoantibody assay. Diabetes 2012;61: 179-186.
22. Diabetes Prevention Trial-Type 1 Diabetes Study Group: Effects of insulin in relatives of patients with type 1 diabetes mellitus. N Engl J Med 2002;346:1685-1691.

23. Skyler JS, Krischer JP, Wolfsdorf J, Cowie C, Palmer JP, Greenbaum C, Cuthbertson D, Rafkin-Mervis LE, Chase HP, Leschek E: Effects of oral insulin in relatives of patients with type 1 diabetes: The Diabetes Prevention Trial-Type 1. Diabetes Care 2005;28:1068-1076.

24. Vehik K, Cuthbertson D, Ruhlig H, Schatz DA, Peakman M, Krischer JP: Long-term outcome of individuals treated with oral insulin: Diabetes Prevention TrialType 1 (DPT-1) oral insulin trial. Diabeset Care 2011;34:1585-1590.

25. Nakayama M, Abiru N, Moriyama H, Babaya N, Liu E, Miao D, Yu L, Wegmann DR, Hutton JC, Elliott JF, Eisenbarth GS: Prime role for an insulin epitope in the development of type 1 diabetes in NOD mice. Nature 2005;435:220-223.

26. Nakayama M, Beilke JN, Jasinski JM, Kobayashi M, Miao D, Li M, Coulombe MG, Liu E, Elliott JF, Gill RG, Eisenbarth GS: Priming and effector dependence on insulin B:9-23 peptide in NOD islet autoimmunity. J Clin Invest 2007;117:1835-1843.

27. Liu E, Yu L, Moriyama H, Eisenbarth GS: Animal models of insulin-dependent diabetes. Methods Mol Med 2004;102:195-212.

28. Steck AK, Johnson K, Barriga KJ, Miao D, Yu L, Hutton JC, Eisenbarth GS, Rewers MJ: Age of islet autoantibody appearance and mean levels of insulin, but not GAD or IA-2 autoantibodies, predict age of diagnosis of type 1 diabetes: Diabetes Autoimmunity Study in the Young. Diabetes Care 2011;34:1397-1399.

29. Parikka V, Näntö-Salonen K, Saarinen M, Simell T, Ilonen J, Hyöty H, Veijola R, Knip M, Simell O: Early seroconversion and rapidly increasing autoantibody concentrations predict prepubertal manifestation of type 1 diabetes in children at genetic risk. Diabetologia 2012;55:1926-1936.

30. Roep BO, Buckner J, Sawcer S, Toes R, Zipp F: The problems and promises of research into human immunology and autoimmune disease. Nat Med 2012;18:48-53.

31. Stadinski B, Kappler J, Eisenbarth GS: Molecular targeting of islet autoantigens. Immunity 2010;32:446-456.

32. Stadinski BD, Zhang L, Crawford F, Marrack P, Eisenbarth GS, Kappler JW: Diabetogenic T cells recognize insulin bound to IAg7 in an unexpected, weakly binding register. Proc Natl Acad Sci U S A 2010;107:10978-10983.

33. Crawford F, Stadinski B, Jin N, Michels A, Nakayama M, Pratt P, Marrack P, Eisenbarth G, Kappler JW: Specificity and detection of insulin-reactive $\mathrm{CD} 4+\mathrm{T}$ cells in type 1 diabetes in the nonobese diabetic (NOD) mouse. Proc Natl Acad Sci U S A 2011;108:16729-16734.

34. Mohan JF, Levisetti MG, Calderon B, Herzog JW, Petzold SJ, Unanue ER: Unique autoreactive $\mathrm{T}$ cells recognize insulin peptides generated within the islets of Langerhans in autoimmune diabetes. Nat Immunol 2010;11:350-354.

35. Michels AW, Ostrov DA, Zhang L, Nakayama M, Fuse M, McDaniel K, Roep BO, Gottlieb PA, Atkinson MA, Eisenbarth GS: Structure-based selection of small molecules to alter allele-specific MHC Class II antigen presentation. J Immunol 2011;187:5921-5930.

36. Battaglia M, Gregori S, Bacchetta R, Roncarolo MG: Tr1 cells: from discovery to their clinical application. Semin Immunol 2006;18:120-127.

37. Roncarolo MG, Gregori S, Battaglia M, Bacchetta R, Fleischhauer K, Levings MK: Interleukin-10-secreting type 1 regulatory $\mathrm{T}$ cells in rodents and humans. Immunol Rev 2006;212:28-50. 
38. Michels AW: Targeting the trimolecular complex. Clin Immunol 2013 March 5 [Epub ahead of print]. pii: S15216616(13)00058-2. doi: 10.1016/j.clim.2013.02.020.

39. Zhang L, Stadinski BD, Michels A, Kappler JW, Eisenbarth GS: Immunization with an insulin peptide-MHC complex to prevent type 1 diabetes of NOD mice. Diabetes Metab Res Rev 2011;27:784-789.

40. Michels AW, von Herrath M: 2011 update: antigen-specific therapy in type 1 diabetes. Curr Opin Endocrinol Diabetes Obes 2011;18:235-240.

41. Liu E, Abiru N, Moriyama H, Miao D, Eisenbarth GS: Induction of insulin autoantibodies and protection from diabetes with subcutaneous insulin B:9-23 peptide without adjuvant. Ann N Y Acad Sci 2002;958:224-227.

42. Fousteri G, Dave A, Bot A, Juntti T, Omid S, von Herrath M: Subcutaneous insulin B:9-23/IFA immunisation induces Tregs that control late-stage prediabetes in NOD mice through IL-10 and IFNgamma. Diabetol 2010;53:1958-1970.

43. Daniel C, Weigmann B, Bronson R, von Boehmer H: Prevention of type 1 diabetes in mice by tolerogenic vaccination with a strong agonist insulin mimetope. J Exp Med 2011; 208:1501-1510.
44. Peakman M, von Herrath M: Antigen-specific immunotherapy for type 1 diabetes: maximizing the potential. Diabetes 2010;59:2087-2093.

45. Mordes JP, Cort L, Norowski E, Leif J, Fuller JM, Lernmark A, Greiner DL, Blankenhorn EP: Analysis of the rat Iddm14 diabetes susceptibility locus in multiple rat strains: identification of a susceptibility haplotype in the Tcrb-V locus. Mamm Genome 2009;20:162-169.

46. Liu Z, Cort L, Eberwine R, Herrmann T, Leif JH, Greiner DL, Yahalom B, Blankenhorn EP, Mordes JP: Prevention of type 1 diabetes in the rat with an allele-specific anti-T-cell receptor antibody: Vbeta13 as a therapeutic target and biomarker. Diabetes 2012;61:1160-1168.

Address correspondence to: Aaron W. Michels, MD Barbara Davis Center for Childhood Diabetes

University of Colorado Denver 1775 Aurora Court, MS A140 Aurora, CO 80045

E-mail: Aaron.Michels@ucdenver.edu 